\title{
Fourth Degree Perineal Laceration
}

National Cancer Institute

\section{Source}

National Cancer Institute. Fourth Degree Perineal Laceration. NCI Thesaurus. Code

C114107.

Injury to perineum involving anal sphincter complex and internal anal sphincter and anal epithelium. (reVITALize) 